\title{
Publisher Correction: Elongation factor ELOF1 drives transcription-coupled repair and prevents genome instability
}

Marit E. Geijer (1D, Di Zhou, Kathiresan Selvam (D), Barbara Steurer, Chirantani Mukherjee $\mathbb{D}^{\mathbb{D}}$, Bastiaan Evers, Simona Cugusi, Marvin van Toorn (1), Melanie van der Woude, Roel C. Janssens, Yannick P. Kok, Wenzhi Gong, Anja Raams, Calvin S. Y. Lo, Joyce H. G. Lebbink, Bart Geverts, Dalton A. Plummer, Karel Bezstarosti, Arjan F. Theil, Richard Mitter, Adriaan B. Houtsmuller, Wim Vermeulen (1D, Jeroen A. A. Demmers (D, Shisheng Li (D,

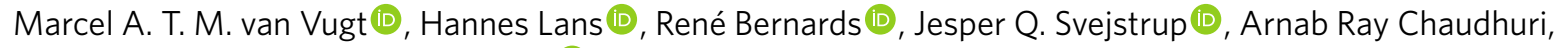
John J. Wyrick and Jurgen A. Marteijn (1)

Correction to: Nature Cell Biology https://doi.org/10.1038/s41556-021-00692-z, published online 9 June 2021

In the version of this Article originally published, there were a couple of errors in reference 38 in the reference list. 'van der Weegan' should instead be 'van der Weegen', and the DOI of the paper should be added to read "van der Weegen, Y. et al. ELOF1 is a transcription-coupled DNA repair factor that directs RNA polymerase II ubiquitylation. Nat. Cell Biol. https://doi.org/10.1038/s41556-021-00688-9 (2021)." The errors have been corrected.

Published online: 23 June 2021

https://doi.org/10.1038/s41556-021-00720-y

( $)$ The Author(s), under exclusive licence to Springer Nature Limited 2021 